\title{
Systemic Lupus Erythematosus Presenting as Immunoglobulin Responsive Macrophage Activation Syndrome
}

\author{
Shamsudeen MOIDEEN¹(D, N.A. UVAIS ${ }^{2}$ D \\ ${ }^{1}$ Department of Internal Medicine, Iqraa International Hospital and Research Centre, Calicut, India \\ ${ }^{2}$ Department of Neuropsychiatry, Iqraa International Hospital and Research Centre, Calicut, India
}

Macrophage activation syndrome (MAS) is a lifethreatening syndrome characterized by cytopenia, organ dysfunction, and coagulopathy associated with an inappropriate activation of macrophages. ${ }^{1}$ Systemic lupus erythematosus (SLE) can present as MAS in the adult population with a prevalence estimated between $0.9 \%$ and $4.6 \% .^{2}$

A 17-year-old female patient presented with high-grade intermittent fever associated with rigors and chills since two months. She also developed spontaneous bleeding from oral cavity for last two weeks. Physical examination showed gross pallor, tachycardia (108 beats/minute) and her blood pressure was $100 / 60 \mathrm{mmHg}$. She was febrile $\left(101^{\circ} \mathrm{F}\right)$. Evidence of fresh gum bleeding without any swelling along with purpural rashes over malar area and vasculitic patches over palms and soles were present. Hepatomegaly was present.

Laboratory routine showed pancytopenia, hyperferritinemia $(>20000 \mathrm{mg} / \mathrm{dL}$ ), increased levels of alanine aminotransferase (101 U/L) and aspartate aminotransferase (329 U/L). Immunological screening was positive for anti-nuclear antibody. Anti-double stranded deoxyribonucleic acid titre was $>150 \mathrm{IU} / \mathrm{mL}$. Abdominal ultrasonography revealed minimal left-sided pleural effusion and mild hepatomegaly. Bone marrow aspirate showed macrophages with hemophagocytosis (Figure 1).

Patient was initially started on broad spectrum antibiotics on day one followed by pulse steroid therapy with methyl prednisolone (1 g/day).

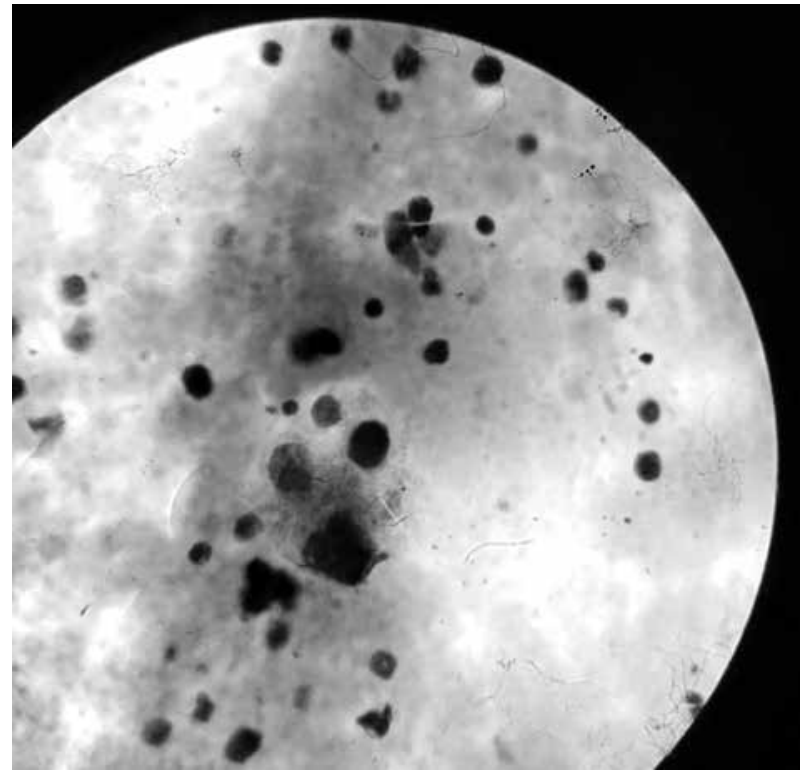

Figure 1. Bone marrow aspirate showed macrophages with hemophagocytosis.

Received: March 14, 2018 Accepted: March 16, 2018 Published online: May 25, 2018

Correspondence: N.A. Uvais, MBBS, DPM. Department of Neuropsychiatry, Iqraa International Hospital and Research Centre, 673009 Calicut, India. Tel: 09562685573 e-mail: druvaisna@gmail.com 
In spite of the above regimen, patient had persistent thrombocytopenia. Intravenous (IV) immunoglobulins (Igs) was started on sixth day and a dose of $2 \mathrm{~g} / \mathrm{kg}$ was administered over five days. On $15^{\text {th }}$ day after starting IV Ig, pancytopenia returned to normal. After one month of IV Ig, she was started on cyclophosphamide pulse therapy. Up to the submission of the manuscript, she had no further complaints or hematological problems.

The diagnosis of MAS is a challenge in patients with SLE. In our case, the diagnosis of MAS secondary to acute SLE was established based on laboratory, clinical, and bone marrow findings. Our case had severe thrombocytopenia, which was considered as a better indicator of MAS than leucopenia and anemia in SLE, and high ferritin level, which was seen to be the strongest indicator to separate MAS from active SLE. ${ }^{3}$ Furthermore, MAS in adult SLE is associated with disease onset in most patients, as in our patient, and this is an important difference with systemic juvenile idiopathic arthritis, in which MAS appears in more advanced stages of the disease.

No standard of care yet exists for MAS complicating SLE. ${ }^{4}$ Case reports supporting the use of a number of immunosuppressive regimens and biological treatments exist in the literature such as high-dose corticosteroids, Igs, cyclophosphamide, cyclosporine and infliximab or rituximab. ${ }^{3,5,6}$ Our patient responded poorly to high-dose steroids, but showed remarkable improvement with IV Igs, followed by IV cyclophosphamide.

\section{Declaration of conflicting interests}

The authors declared no conflicts of interest with respect to the authorship and/or publication of this article.

\section{Funding}

The authors received no financial support for the research and/or authorship of this article.

\section{REFERENCES}

1. Henter JI, Elinder G, Söder O, Ost A. Incidence in Sweden and clinical features of familial hemophagocytic lymphohistiocytosis. Acta Paediatr Scand 1991;80:428-35.

2. Fukaya S, Yasuda S, Hashimoto T, Oku K, Kataoka H, Horita $\mathrm{T}$, et al. Clinical features of haemophagocytic syndrome in patients with systemic autoimmune diseases: analysis of 30 cases. Rheumatology (Oxford) 2008;47:1686-91.

3. Parodi A, Davì S, Pringe AB, Pistorio A, Ruperto $\mathrm{N}$, Magni-Manzoni $S$, et al. Macro-phage activation syndrome in juvenile systemic lupus erythematosus: a multinational multicenter study of thirty-eight patients. Arthritis Rheum 2009;60:3388-99.

4. Dhote R, Simon J, Papo T, Detournay B, Sailler L, Andre $\mathrm{MH}$, et al. Reactive hemoph-agocytic syndrome in adult systemic disease: report of twenty-six cases and literature review. Arthritis Rheum 2003;49:633-9.

5. McCann LJ, Hasson N, Pilkington CA. Macrophage activation syndrome as an early presentation of Lupus. J Rheumatol 2006;33:438-40.

6. Ravelli A, Viola S, De Benedetti F, Magni-Manzoni S, Tzialla C, Martini A. Dramatic efficacy of cyclosporine $A$ in macrophage activation syndrome. Clin Exp Rheumatol 2001;19:108. 